\title{
Evaluasi Kinerja Bank Sampah "Sekar Arum “ di Perumahan Wilis Indah II, Kelurahan Pojok, Kecamatan Mojoroto, Kota Kediri
}

\author{
Pratama Sandi Alala ${ }^{1}$, Agus Budianto ${ }^{2}$ \\ ${ }^{1}$ Jurusan Teknik Lingkungan, Fakultas Teknik Sipil dan Perencanaan, Institut Teknologi Adhi Tama Surabaya \\ ${ }^{2} J u r u s a n$ Teknik Kimia, Fakultas Teknik Industri, Institut Teknologi Adhi Tama Surabaya \\ Email: ${ }^{1}$ sandi@itats.ac.id, ${ }^{2}$ budichemical@itats.ac.id
}

\begin{abstract}
Waste Bank is a place for receiving waste that has been selected. The Waste Bank was established because of the community's thought to improve waste management by making specific innovations. The increase in the volume of waste generation creates problems with the capacity of the final processing plant. One way to manage waste is by having a waste bank. One of the waste banks in Kediri City is the Sekar Arum Waste Bank in the Wilis Indah II housing estate, Pojok Village, Mojoroto District, Kediri City. The characteristics of solid waste through the Sekar Arum waste bank in Wilis Indah II housing, corner sub-district, Mojoroto sub-district, Kediri city for the dominant types of garbage being managed are plastic and paper waste, with a percentage of 86.5 per cent. In comparison, the remaining 15.5 per cent is a type of waste-used cans. The average generation of paper waste was 589.7 / $\mathrm{kg}$ for paper 373.5 / kg for plastics. Waste that has been successfully reduced in a waste bank with an average number of customers of 130 people has a total waste receipt of $30.2 \mathrm{~kg} / \mathrm{month}$
\end{abstract}

Keywords: Waste, Waste Bank Performance of Sekar Arum, Wilis Indah II Housing, Pojok Urban Village, Mojoroto District, Kediri City

\begin{abstract}
Abstrak
Bank Sampah adalah tempat penerimaan sampah yang telah dipilih. Bank Sampah berdiri karena adanya pemikiran masyarakat untuk memperbaiki pengelolaan sampah, dengan melakukan inovasi tertentu. Peningkatan volume imbulan sampah menimbulkan permasalah pada kapasitas tempat pemrosesan akhir. Salah satu cara untuk mengelola sampah adalah dengan adanya bank sampah. Salah satu bank sampah yang ada di Kota Kediri adalah Bank Sampah Sekar Arum di perumahan Wilis Indah II, Kelurahan Pojok, Kecamatan Mojoroto, Kota Kediri. Karakterisitik persampahan melalui bank sampah sekar arum di perumahan wilis indah II, kelurahan pojok, kecamatan mojoroto, kota kediri untuk jenis sampah yang dominan dikelola adalah plastik dan sampah kertas, dengan prosentase 86,5 persen, sedangkan sisanya sekitar 15,5 persen merupakan sampah jenis kaleng bekas. Timbulan rata-rata sampah kertas yaitu 589,7/kg untuk kertas 373,5/kg untuk plastik. Sampah yang berhasil direduksi pada bank sampah dengan jumlah nasabah rata-rata 130 orang memiliki jumlah penerimaan sampah sebesar $30,2 \mathrm{~kg} / \mathrm{bulan}$.
\end{abstract}

Kata Kunci: Sampah, Kinerja Bank Sampah Sekar Arum, Perumahan Wilis Indah II, Kelurahan Pojok, Kecamatan Mojoroto, Kota Kediri

\section{Pendahuluan}

Sampah adalah sesuatu yang merupakan salah satu efek aktifitas manusia namun kesadaran masyarakat pada persoalan lingkungan akibat sampah masih perlu selalu ditingkatkan. Memang disadari atau tidak sampah-sampah itu ternyata memag menciptakan polusi. Berdasarkan data yang diambil dari Dinas Kebersihan dan Pertamanan masyarakat kota Kediri setiap harinya menghasilkan $425 \mathrm{~m}^{3}$ sampai dengan $450 \mathrm{~m}^{3}$ sampah yang terdiri dari 56\% sampah organik, 26\% sampah anorganik dan 18\% sampah beracun yang berasal dari tiga kecamatan yaitu : Mojoroto, Kota, Pesantren. Salah satu bentuk pengelolaan sampah adalah pengurangan sampah yang dapat dilakukan oleh setiap orang [1] seperti bank sampah. Bank sampah ini merupakan salah satu alternative terbaik mengurangi timbulan sampah [2]. Hal ini perlu dukungan masyarakat dengan perilaku yang mendukung 
kemudahan pengelolaan sampah [3]. Perkembangan bank sampah ditentukan oleh sikap warga terhadap bank sampah, sehingga sosialisasi dan edukasi masih dibutuhkan dalam pengembangan bank sampah [4]. Bank sampah di Yogyakarta dapat mengurangi timbulan sampah hingga 97\% [5].

Beberapa bank sampah tidak bisa bertahan lama dikarenakan berbagai tantangan pada permasalahan. Bank Sampah Perumahan Wilis Indah II jl. 1-2 No. 19 RT.01 RW.07 Kelurahan Pojok, Kecamatan Mojoroto, Kota Kediri merupakan bank sampah yang mampu berdiri dan bertahan dengan berbagai permasalahannya. Bank Smpah dapat didirikan dengan konsep 3R, yang dikenaldengan Reduce, Reuse dan Recycle. [6]. Jenis dan kerumita pengelolaan bank sampah detentukan oleh budaya, dan jenis sampah [7]. Pemberdayaan masyarakat menjadi Prinsip utama dalam pengembangan bank sampah [8]. Hal ini menimbulkan daya Tarik agar dijadikan potret yang baik untuk membangun suatu bank sampah ditempat lainnya. Beberapa hal yang perlu jawaban adalah bagaimana konsep Evaluasi Kinerja Bank Sampah Sekar Arum, bagaimana faktor kekuatan dan kelemahan, tantangan dan peluang Bank Sampah Sekar Arum, Kelurahan Pojok, Kecamatan Mojoroto, Kota Kediri pada saat penelitian ini; bagaimana Evaluasi Kinerja Bank Sampah Sekar Arum; bagaimana kinerja ekonomi Bank Sampah Sekar Arum.

Tujuan Penelitian ini adalah mengidentifikasi Evaluasi Kinerja Bank Sampah Sekar Arum; melakukan evaluasi ekonomi bank sampah terhadap 3 parameter ekonomi yaitu, Break Event Point (BEP), Rate Of Return (ROR), Pay Out Time (POT) mengetahui konsep Evaluasi Kinerja Bank Sampah Sekar Arum; mengetahui faktor kekuatan dan kelemahan, tantangan dan peluang Bank Sampah Sekar Arum, Kelurahan Pojok, Kecamatan Mojoroto, Kota Kediri terkait program Bank Sampah. Penelitian ini diharapkan memberikan manfaat terhadap penerapan ilmu yang diperoleh sebagai mahasiswa Magister Teknik Lingkungan Institut Teknologi Adhi Tama Surabaya. Penelitian ini juga diharapkan dapat menambah wawasan keilmuan dan pengalaman penelitian dalam bidang studi teknik lingkungan. Manfaat lain adalah sebagai masukan dan bahan pertimbangan bagu penelitian selanjutnya dan sebagai pengendaharaan perpustakaan untuk kepentingan ilmiah di Magister Teknik Lingkungan Institut Teknologi Adhi Tama Surabaya. Mnfaat tambahan adalah memberikan kontribusi yaitu menjadikan bank sampah lebih baik, dengan cara menyusun rekomendasi dalam upaya meningkatkan pengelolaan program bank sampah, untuk mengetahui peran bank sampah pada masyarakat sehingga anggota bank sampah dapat mengintrospeksi diri agar lebih baik, serta untuk dapat mengetahui besar nilai ekonomi yang dihasilkan oleh bank sampah tersebut. Hasil penelitian juga memberi masukan kepada pemerintah dalam pengambilan kebijakan dan lebih menggalakan bank sampah lain. Sehingga mambantu mengatasi masalah sampah dan sampah dapat dijadikan aset berharga bagi masyarakat danmemberikan informasi atau gambaran bagi peneliti lainnya mengenai cara mengidentifikasi faktor pendukung dan penghambat pengelolaan program bank sampah, untuk dapat mengetahui nilai ekonomi yang dihasilkan oleh bank sampah serta dapat merumuskan atau menyusun rekomendasi dalam upaya meningkatkan pengelolaan program bank sampah.

\section{Metode Penelitian}

Penelitian ini bersifat deskriptif kualitatif yang bertujuan untuk melihat gambaran proses evaluasi kinerja masyarakat dalam mengelola sampah dengan sistem bank sampah. Subjek dan Objek Penelitian adalah Bank Sampah Sekar Arum, Kelurahan Pojok, Kecamatan Mojoroto, Kota Kediri. Pengumpulan Data dilakukan terhadap jenis sampah yang diterima, peserta bank sampah, produk yang dapat dijual dan dimanfaatkan ulang, kondisi organisasi di lakukan dengan Analisa SWOT, dan data pemberdayaan Masyarakat melalui Pengelolaan Sampah di kelurahan Pojok. Penelitian ini menggunakan metode data dengan kuesioner dan pengamatan langsung dilapangan. Analisa dokumen dan wawancara, yang akan menghasilkan data berupa data primer dan data sekunder.

Analisis data dalam penelitian ini dilakukan untuk mencapai tujuan penelitian, data yang sudah terkumpul dan diklasifikasikan secara sistematis. Selanjutnya dilakukan analisis dengan metode analisis SWOT (Strenght, Weakness, Opportunity dan Treath). Analisis SWOT merupakan suatu cara atau metode untuk mengientifikasi faktor pendukung dan penghambat pengelolaan program Bank Sampah Sekar Arum. 


\section{Hasil dan Pembahasan}

Kelurahan Pojok merupakan salah satu kelurahan yang berada di kecamatan Mojoroto. Kecamatan Mojoroto merupakan salah satu kecamatan yang ada disebelah Barat Kota Kediri. Luas Wilayah Kecamatan Mojoroto adalah 24,6 Km².

Secara administrative kelurahan pojok, kecamatan Mojoroto kota Kediri mempunya batas wilayah sebagai berikut bagian utara berbatasan Kecamatan Banyakan. Bagian timur berbatasan dengan kecamatan Kota, Bagian selatan berbatasan dengan Kecamatan Semen. Bagian baratberbatasan dengan Gunung Wilis. Kelurahan pojok merupakan kelurahan terluas pada Kecamatan Mojoroto Kelurahan Pojok memiliki luas wilayah $5,15 \mathrm{Km}^{2}$. kelurahan Dermo merupakan wilayah tersempit, Kelurahan ini dengan luas wilayah $0,66 \mathrm{Km}^{2} .14$ kelurahan di kecamatan Kota berbentuk kelurahan bukan Desa. Bila di lihat dari penggunanya, Wilayah di Kecamatan Mojoroto terbagi menjadi dua macam yaitu persawahan dan pemukiman dengan luas masing-masing 711,8 Ha dan 800,08 Ha.

\section{Profil Bank Sampah "Sekar Arum” Kota Kediri}

Bank sampah sekar arum di kota Kediri di resmikan pada bulan september 2013 . pemerintah punya program karna tempat sampah di perumahan wilis II sudah over load, jadi akhirnya dibentuknya bank sampah. Masyarakat perumahan wilis II melihat sampah dimana-mana akhir bergerak mendirikan bank sampah. Bank sampah sekar arum yang di ketuai oleh ibu siti dan sampe sekarang jumlah nasabah lebih dari 130 nasabah. Setiap bulan masyarakat mengadakan sosialisasi mengenai sampah di adakan di perumahan wilis II kota Kediri. Sampah yang di manfaatkan adalah sampah yang bisa didaur ulang. Bank sampah juga dapat menjadi sarana dalam perekonomian masyarakat agar dapat mandiri dan yang terpenting ialah mengubah perilaku masyarakat agar lebih peduli lingkungan.

\section{Pengelolaan Bank Sampah Perumahan Wilis II Kota Kediri}

Hasil observasi dan wawancara terhadap masyarakat di perumahan wilis indah II kota Kediri, dapat dipaparkan oleh peneliti adalah Rencana pengembangan program bank sampah, Partisipasi masyarakat, Sosialisasi Pengorganisasian, Struktur organisasi program bank sampah, Kerjasama antara bank sampah dengan pihak terkait. Kegiatan bank sampah sekar arum kota kediri terdiri dari penyetoran sampah yang dilakukan setiap hari sabtu dimulai pukul 07:00 WIB. Nasabah bank sampah sekar arum Kota Kediri menyetorkan sampah padat yang sudah dilakukan pemilahan dari masingmasing rumah, jenis sampah tersebut adalah botol minuman, kardus, kaleng, duplek, sak semen dll. Selanjutnya Penimbangan Sampah yang sudah disetor ke bank sampah kemudian dilakukan penimbangan secara keseluruhan sesuai dengan jenisnya sebelum di angkut ke pengepul.

Kegiatan selanjutnya adalah pengangkutan sampah anorganik atau sampah bekas yang sudah di setorkan kepada bank sampah dan sudah dipilah oleh masing-masing nasabah, karna pihak dari bank sampah sekar arum belum mempunyai kendaraan pribadi untuk mengangkut sampah kepada pengepul, sehingga sampah tersebut diangkut dengan menggunakan kendaraan truk yang di sewa oleh bank sampah yang dilakukan setiap 2 bulan. Kegiatan lainnya adalah Ide kreatif dari pengrurus Bank sampah sekar arum juga melakukan proses daur ulang sampah anorganik, sebagian sampah anorganik seperti botol minuman, plastik kemasan sabun dan kemasan minuman atau makanan. Dengan keuletan dan kreatifisa mereka bisa membut berbagai macam kerajinan, sekaligus menjadikan nilai ekonomi yang cukup tinggi. 
Tabel 1. Daftar Harga Sampah

\begin{tabular}{|c|c|c|c|c|c|c|c|}
\hline \multirow{2}{*}{$\begin{array}{l}\text { No } \\
1\end{array}$} & \multirow{2}{*}{$\begin{array}{l}\text { Sampah Padat } \\
\text { Kardus }\end{array}$} & \multicolumn{2}{|c|}{ Harga/Kg } & \multirow{2}{*}{$\begin{array}{c}\text { No } \\
16\end{array}$} & \multirow{2}{*}{$\begin{array}{l}\text { Sampah Padat } \\
\text { Botol ABC }\end{array}$} & \multicolumn{2}{|c|}{ Harga/Kg } \\
\hline & & $\mathrm{Rp}$ & 2,300 & & & $\mathrm{Rp}$ & 200 \\
\hline 2 & HVS & $\mathrm{Rp}$ & 2,300 & 17 & Botol kecap & $\mathrm{Rp}$ & 700 \\
\hline 3 & Duplek & $\mathrm{Rp}$ & 1,100 & 18 & Boram & $\mathrm{Rp}$ & 1,800 \\
\hline 4 & Gembos & $\mathrm{Rp}$ & 1,000 & 19 & Sak semen & $\mathrm{Rp}$ & 400 \\
\hline 5 & HD & $\mathrm{Rp}$ & 800 & 20 & Ps kaca & $\mathrm{Rp}$ & 3,000 \\
\hline 6 & Kaleng & $\mathrm{Rp}$ & 1,300 & 21 & Besi & $\mathrm{Rp}$ & 2,000 \\
\hline 7 & Putihan & $\mathrm{Rp}$ & 4,300 & 22 & Aluminium & $\mathrm{Rp}$ & 10,000 \\
\hline 8 & Rosok & $\mathrm{Rp}$ & 1,600 & 23 & Krasan & $\mathrm{Rp}$ & 500 \\
\hline 9 & Plastik putih & $\mathrm{Rp}$ & 1,500 & 24 & Koran & $\mathrm{Rp}$ & 2,500 \\
\hline 10 & Gelas bersih & $\mathrm{Rp}$ & 7,000 & 25 & Baja & $\mathrm{Rp}$ & 2,300 \\
\hline 11 & Seng & $\mathrm{Rp}$ & 700 & 26 & Bak Warna & $\mathrm{Rp}$ & 3,000 \\
\hline 12 & Botol kecil & $\mathrm{Rp}$ & 300 & 27 & Botol sosro & $\mathrm{Rp}$ & 150 \\
\hline 13 & Pet warna & $\mathrm{Rp}$ & 1,800 & 28 & Aki & $\mathrm{Rp}$ & 8,000 \\
\hline 14 & Plastik tebal & $\mathrm{Rp}$ & 800 & 29 & Botol bensin & $\mathrm{Rp}$ & 1,000 \\
\hline 15 & Pet bersih & $\mathrm{Rp}$ & 3,500 & & & & \\
\hline
\end{tabular}

\section{ANALISIS MATRIK SWOT}

Analisis SWOT adalah metode yang digunakan untuk mengidentifikasi faktor pendukung dan penghambat pengelolaan program bank sampah. Berikut adalah kuadran SWOT IFAS dan EFAS bank sampah di Perumahan Wilis Indah II, Kelurahan Pojok, Kecamatan Mojoroto, Kota Kediri.

\section{IFAS (Internal Factor Analysis Strategy)}

Tabel 2. Hasil Kuisioner kekuatan Bank Sampah

\begin{tabular}{|c|c|c|c|c|c|}
\hline No & Faktor & Setuju & $\begin{array}{l}\text { Tidak } \\
\text { Setuju }\end{array}$ & Total & Rating \\
\hline 1 & Kemampuan bank sampah mengurangi timbunan sampah & 110 & 18 & 128 & 4 \\
\hline 2 & Kemampuan bank sampah menambah kas warga & 75 & 53 & 128 & 3 \\
\hline 3 & Bank sampah berpotensi meningkatkan kekompakan warga & 98 & 30 & 128 & 4 \\
\hline
\end{tabular}

Tabel 3. Matrik SWOT kekuatan Bank Sampah

\begin{tabular}{|c|c|c|c|c|}
\hline No. & Faktor & Rating & Bobot & Total \\
\hline 1 & Kemampuan bank sampah mengurangi timbunan sampah & 4 & 0,44 & 1,76 \\
\hline 2 & Kemampuan bank sampah menambah kas warga & 3 & 0,23 & 0,69 \\
\hline 3 & Bank sampah berpotensi meningkatkan kekompakan warga & 4 & 0,33 & 1,32 \\
\hline Total & & & 1,00 & 3,77 \\
\hline
\end{tabular}


Tabel 4. Hasil Kuisioner Kelemahan Bank Sampah

Weakness (Kelemahan)

\begin{tabular}{|c|c|c|c|c|c|}
\hline No. & Faktor & Setuju & $\begin{array}{l}\text { Tidak } \\
\text { Setuju }\end{array}$ & Total & Rating \\
\hline 1 & $\begin{array}{l}\text { Harga jual kembali sampah (barang bekas) yang dikumpulkan } \\
\text { terlalu rendah sehingga berdampak pada keuntungan bank } \\
\text { sampah dan pemasukan nasabah }\end{array}$ & 93 & 35 & 128 & 4 \\
\hline 2 & $\begin{array}{l}\text { Mahalnya harga karung untuk pengemasan sampah (barang } \\
\text { bekas) }\end{array}$ & 38 & 90 & 128 & 2 \\
\hline 3 & Tingkat keaktifan anggota bank sampah & 72 & 56 & 128 & 3 \\
\hline
\end{tabular}

Tabel 5. Matrik SWOT Kelamahan Bank Sampah

Weakness (Kelemahan)

\begin{tabular}{lllll}
\hline No & Faktor & Rating & Bobot & Total \\
\hline 1 & $\begin{array}{l}\text { Harga jual kembali sampah (barang bekas) yang dikumpulkan terlalu } \\
\text { rendah sehingga berdampak pada keuntungan bank sampah dan } \\
\text { pemasukan nasabah }\end{array}$ & 4 & $-0,30$ & $-1,20$ \\
2 & Mahalnya harga karung untuk pengemasan sampah (barang bekas) & 2 & $-0,30$ & $-0,60$ \\
3 & Tingkat keaktifan anggota bank sampah & 3 & $-0,40$ & $-1,20$ \\
Total & & & $-\mathbf{1 , 0 0}$ & $\mathbf{- 3}$ \\
\hline
\end{tabular}

EFAS (Eksternal Factor Analysis Strategy)

Tabel 6. Hasil Kuesioner Peluang Bank Sampah

Opportunity (Peluang)

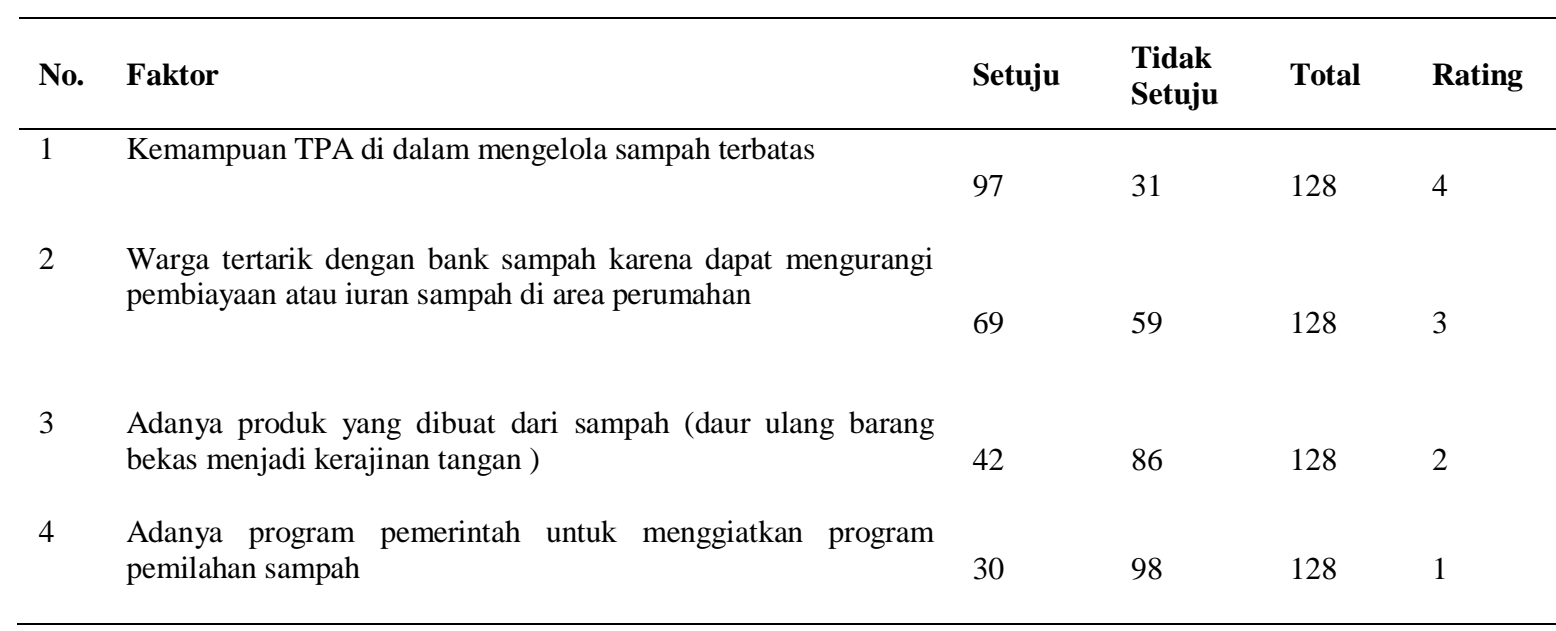


Tabel 7. Matrik SWOT Peluang Bank Sampah

\section{Opportunity (Peluang)}

\begin{tabular}{lllll}
\hline No. & Faktor & Rating & Bobot & Total \\
\hline 1 & Kemampuan TPA di dalam mengelola sampah terbatas & 4 & 0,20 & 0,80 \\
2 & $\begin{array}{l}\text { Warga tertarik dengan bank sampah karena dapat mengurangi } \\
\text { pembiayaan atau iuran sampah di area perumahan }\end{array}$ & 3 & 0,30 & 0,90 \\
3 & $\begin{array}{l}\text { Adanya produk yang dibuat dari sampah (daur ulang barang bekas } \\
\text { menjadi kerajinan tangan ) }\end{array}$ & 2 & 0,10 & 0,20 \\
4 & $\begin{array}{l}\text { Adanya program pemerintah untuk menggiatkan program pemilahan } \\
\text { sampah }\end{array}$ & 1 & 0,40 & 0,40 \\
Total & & & $\mathbf{1 , 0 0}$ & $\mathbf{2 , 3 0}$ \\
\hline
\end{tabular}

Threat (Penghambat / Ancaman)

Tabel 8. Hasil Kuisioner Penghambat Bank Sampah

\begin{tabular}{|c|c|c|c|c|c|}
\hline No. & Faktor & Setuju & $\begin{array}{l}\text { Tidak } \\
\text { Setuju }\end{array}$ & Total & Rating \\
\hline \multirow[t]{2}{*}{1} & Kurangnya minat warga untuk menjadi nasabah bank sampah & & & & \\
\hline & & 86 & 42 & 128 & 3 \\
\hline 2 & $\begin{array}{l}\text { Bersaing dengan pemulung (rombeng keliling) dalam penjualan } \\
\text { sampah (barang bekas) }\end{array}$ & 55 & 73 & 128 & 2 \\
\hline
\end{tabular}

Threat (Penghambat / Ancaman)

Tabel 9. Matrik SWOT Penghambat Bank Sampah

\begin{tabular}{llccc}
\hline No. & Faktor & Rating & Bobot & Total \\
\hline 1 & Kurangnya minat warga untuk menjadi nasabah bank sampah & 3 & $-0,70$ & $-2,10$ \\
2 & $\begin{array}{l}\text { Bersaing dengan pemulung (rombeng keliling) dalam penjualan sampah } \\
\text { (barang bekas) }\end{array}$ & 2 & $-0,30$ & $-0,60$ \\
Total & & $\mathbf{- 1 , 0 0}$ & $\mathbf{- 2 , 7}$ \\
\hline
\end{tabular}

\begin{tabular}{ll}
\hline Penilaian Rating & \\
\hline $1-32$ responden & 1 \\
\hline $33-64$ responden & 2 \\
\hline $65-96$ responden & 3 \\
\hline $97-128$ responden & 4 \\
\hline
\end{tabular}

Berdasarkan hasil yang didapat dari analisis intrnal dan eksternal pada tabel 9. seperti dituliskan di atas, hasilnya dapat dirangkum sebagai berikut skor total kekuatan 3,37; skor total kelemahan -3,00; skor total peluang 2,30; skor total ancaman -2,7. Hasil tersebut perhitungan strategi untuk berkembang lebih lanjut memerlukan penegasan dari adanya posisi dalam Salib sumbu yaitu antara kekuatan dan 
kelemahan, maupun peluang dan ancaman yang kesemuanya di gambarkan dalam garis positif dan negatif.

Dari analisis tersebut diatas bahwasannya faktor kekuatan lebih besar dari faktor kelemahan dan faktor peluang lebih kecil dari faktor ancaman. Menentukan posisi Bank Sampah Sekar Arum dapat di gambar sebagai Matrik SWOT yang dapat dilihat pada gambar 4.9. untuk mencari koordinatnya, dapat dicari dengan cara sebagai berikut Koordinat Analisis Internal diungakp dalam bentuk Skor Total Kekuatan - Skor Total Kelemahan $=3,37-3,00=0,37$. Koordinat Analisis Eksternal Skor Total Peluang - Skor Total Ancaman = 2,30-2,7= -0,4. Jadi titik koordinatnya terletak pada $(0,37 ;-0,4)$.

\section{Kesimpulan}

Hasil penelitian terhadap bank sampah Sekar Arum menujukkaan jenis sampah yang banyak diterima oleh bank sampahadalah jenis plastik, kertas dan kaleng. Penerimaan kaleng, plastic dan kertas secara berturutturut adalah 15,5\%, dan 86,5 untuk plastic dan kertas. Penerimaan sampah utama adalah plastic dan kertas 589,7 Kg/bulan dan kaleng sebesar 30,2 kg/bulan. Hasil Analisa SWOT menujukkan posisi bank sampah Sekar Arum padai titik koordinat $(0,37 ;-0,4)$.

\section{Referensi}

[1] P. R. Indonesia, "Undang-undang republik indonesia nomor 18 tahun 2008 tentang pengelolaan sampah," Sekretariat Negara, Jakarta, 2008.

[2] D. Asteria and H. Heruman, "Bank sampah sebagai alternatif strategi pengelolaan sampah berbasis masyarakat di Tasikmalaya (Bank Sampah (Waste Banks) as an alternative of community-based waste management strategy in Tasikmalaya)," Jurnal Manusia dan Lingkungan, vol. 23, no. 1, pp. 136-141, 2016.

[3] R. Bidullah, "PEMBERDAYAAN MASYARAKAT DALAM BERPERILAKU HIDUP BERSIH dan SEHAT (PHBS) MELALUI GERAKAN MORAL "PINASA" DI KABUPATEN BANGGAI," 2018.

[4] Y. Nugraheni and A. Y. Widyaningrum, "Dinamika Sikap Warga atas Program CSR Bank Sampah Gunung Anyar Surabaya," Jurnal Studi Komunikasi, vol. 3, no. 1, pp. 41-56, 2019.

[5] S. Haryanti, E. Gravitiani, and M. Wijaya, "Studi Penerapan Bank Sampah dalam Upaya Pengelolaan Lingkungan Hidup di Kota Yogyakarta," Bioeksperimen: Jurnal Penelitian Biologi, vol. 6, no. 1, pp. 60-68, 2020.

[6] P. A. Shentika, "Pengelolaan bank sampah di Kota Probolinggo," Jurnal Ekonomi dan Studi Pembangunan, vol. 8, no. 1, pp. 92-100, 2016.

[7] P. A. A. Levi, "Gerakan Keadilan Lingkungan Studi Kasus Di Bank Sampah Gemah Ripah Dusun Badegan Bantul," Tersedia pada: http://eprints. uny. ac. id. Diakses, vol. 2, 2012.

[8] B. Suwerda, "Bank Sampah (kajian teori dan penerapan)," Yogyakarta: Pustaka Rihama, 2012. 
102 Jurnal Teknologi dan Manajemen Vol 1, No 2, Juli 2020: 95-102

- Halaman ini sengaja dikosongkan - 